\title{
«Vuestras palabras me serán espejo». Reflejos neoplatónicos entre Francisco de Aldana y Luis Cernuda
}

\author{
Giuliana Calabrese \\ Università degli Studi di Milano-Bicocca \\ giuliana.calabrese@unimib.it
}

Recepción: 09/04/2018, Aceptación: 19/05/2018, Publicación: 11/12/2018

\begin{abstract}
Resumen
En este artículo se evidencia la huella de Aldana sobre la escritura poética de Cernuda a través de una lectura de unas imágenes literarias de derivación neoplatónica. El contexto literario renacentista y el pensamiento ficiniano que influyen en los versos de Aldana, le permiten reflejar en ellos una auténtica filosofía luminosa que converge en la imagen del espejo, favoreciendo fenómenos de refracción que conectan el hombre y la divinidad o el hombre y la memoria por medio de una recíproca iluminación. Cernuda, por su parte, gracias al acercamiento a los poetas metafísicos ingleses, trae a su presente también a Aldana, identificando en sus versos una profunda capacidad de correlación entre la realidad visible y la invisible. Recuperando la misma imagen literaria del espejo y proporcionando otros ejemplos de reflexión física, el poeta sevillano crea un sistema simbólico gracias al cual se evidenciará también en su poética la conciencia de la fractura propia del ser umano y la aspiración (neoplatónica) a la reunificación.
\end{abstract}

Palabras clave

Francisco de Aldana; Luis Cernuda; neoplatonismo; luz; espejo

\begin{abstract}
"Vuestras palabras me serán espejo". Neoplatonic reflection between Francisco de Aldana y Luis Cernuda

In this article we want to show Aldana's influence on the poetry of Cernuda through some literary images of Neoplatonic derivation. The Renaissance literary context and the ficinian philosophy that influence the verses of Aldana, allow him to write a sort of luminous philosophy; it converges in the image of the mirror, favoring refraction
\end{abstract}


phenomena that connect man and divinity or man and memory through reciprocal lighting. Cernuda, on the other hand, thanks to his knowledge of English metaphysical poets, brings to his present also Aldana, identifying in his verses a deep capacity for correlation between visible and invisible reality. Recovering the same literary image of the mirror and providing other examples of physical reflection, the Sevillian poet creates a symbolic system thanks to which it will also be evident in his poetic the awareness of the fracture of the human being and the (neoplatonic) aspiration to reunification.

\section{Keywords}

Francisco de Aldana; Luis Cernuda; Neoplatonismo; light; mirror

«Amo ante todo la luz», afirmaba Ficino en Quid sit lumen ${ }^{1}$ y los estudios dedicados al pensamiento ficiniano han dejado claro este núcleo fundamental de su obra desde hace tiempo. ${ }^{2}$ Como se sabe, más allá de asegurar cierto nivel de coherencia dentro de su corpus doctrinal, el elemento lumínico en el pensamiento de Ficino, derivado de un origen platónico y de una reelaboración plotiniana, cumple la función de vínculo entre los diferentes elementos del universo, así como de símbolo estético que permite alcanzar la divinidad. Este modelo ontológico se basaría, por lo tanto, en el «enunciado convergente de irradiación luminosa y amor celeste constitutivos del ropaje de un universo en el que percibimos la fuerza creadora y conservadora de toda realidad».3

1. Marsilio Ficino (2004: 337).

2. Véase Rabassini (2006), Reynaud y Galland (2008) y Vasoli (1998).

3. José Lara Garrido (1985: 88); las citas proceden de su «Introducción» a la edición de Aldana (Poesías castellanas completas, Madrid, Cátedra, 1985). «La mirada cobra su sentido en su ejercicio mismo que el don de la luz hace posible. Ficino toma esta idea de Platón. La metáfora platónica apuntaba al nexo entre la visión, como símbolo de la inteligencia, y la luz de las ideas. Ficino conserva este simbolismo de la transparencia de la idea pero para él la luz es sobre todo medio de intelegibilidad que incita y forma a la mirada y que forma también, hace presentes, a los cuerpos: 
Sin embargo, la diferencia que el filósofo italiano elabora con respecto a Plotino consiste en la posición central que el primero le otorga al hombre dentro del sistema de la creación, debida a la naturaleza del alma y a la relación entre sus diferentes facultades ${ }^{4} \mathrm{y}$ al recuerdo del mismo origen divino del alma gracias a la mens, que «puede captar la verdad por la contemplación directa de las ideas supracelestiales» $;^{5}$ de esta manera, recordando su procedencia divina, el alma intenta ascender a la divinidad luchando contra su componente terrenal. A partir de esta base platónica se desarrolla la reflexión ficiniana sobre la luz, símbolo estético, como ya se ha recordado antes, de dicha relación del alma humana con la divinidad. Por supuesto, casi todas las tradiciones espirituales están colmadas de ejemplos que explican la analogía entre símbolos luminosos y figuras divinas, empezando por el fiat lux cristiano. Lo que aquí interesa es, a través de una primera lectura ficiniana, analizar el símbolo poético de la luz para trazar una línea que sale de la poética luminosa del Renacimiento y que enlaza la poesía de Francisco de Aldana ${ }^{6}$ y la de Luis Cernuda, precisamente a través de conexiones lumínicas y de cierta natura especular que se intentará vislumbrar y que permitirán reconocer en los versos de los dos poetas los resultados estéticos y literarios de una tensión deseante compartida a pesar de los siglos que los separan.

Las manifestaciones de la luz en la poesía de Francisco de Aldana, que deriva precisamente de esa filosofía luminosa neoplatónica, se enriquecen gracias a lo que en palabras de Robert Klein se podría llamar «ciencia de transmisión de los rayos luminosos» ${ }^{7}$ y que hacen evidente la relación entre alma y luz. ${ }^{8}$ Más allá de la elaboración poética del pensamiento neoplatónico en general de parte de Aldana, lo que aquí interesa es explicar cómo el funcionamiento de la luz cual vínculo del mundo se manifiesta en sus versos y se concretiza en la imagen literaria del espejo (y en su relación con las propiedades físicas de la luz y con los fenómenos de refracción). Ya lo ha afirmado Chastel: «para el neoplatonismo que identifica la luz y

'la luz única del sol se presenta a los ojos pintada de colores y de figuras de todos los cuerpos iluminados por ella’" (Bosco y Jiménez 2004: 29).

4. Véase Panofsky (2008).

5. Panofsky (2008: 196).

6. «La crianza del poeta a orillas del Arno, a la vera de la Academia de Ficino, pudo tener una importancia capital en su personal lenguaje poético. Entre otras cosas, propició su familiaridad con el neoplatonismo que en buena medida le vino de la mano de Benedetto Varchi, a quien le unió el trato personal, y con quien llegó a dirigirse e intercambiar sonetos, que después verían la luz en Florencia (1563). Aunque Marsilio Ficino había mantenido sin titubeos la separación entre la vista y los demás sentidos en el amor a la Belleza, a Varchi, en cambio, poeta como Aldana, no podían ocultársele las dificultades que en la práctica conllevaba el divorcio del amor celeste y ferino, consciente de que entre los dos extremos existe un abanico nada despreciables de situaciones intermedias. Entre ellas se situará un poeta como Aldana» (Fosalba 1992: 180).

7. Klein (1982: 217).

8. «El cuerpo del alma del mundo está constituido por una luz que surge de él antes que cualquier otra criatura, antes que el cielo. Esta luz es también el vehículo de las almas humanas» (Klein 1982: 69). 
el espíritu, el espejo proporciona una imagen inagotable del conocimiento y de la conciencia; ${ }^{9}$ y Cerrón Puga, entre otros, lo subraya a propósito de la poesía de Aldana: 'a través del espejo se refleja la luz divina en los mortales ${ }^{10}{ }_{1}{ }^{11}$

\section{La imagen del espejo en Francisco de Aldana}

La función de los espejos en los versos de Aldana es precisamente la de revelar la naturaleza luminosa del alma del mundo y, de cierta manera, de facilitar la conexión (o la reunión) entre el hombre y la luz divina. Son por lo menos dos los significados que convergen en los versos de Aldana a través del este fenómeno de refracción lumínica: el primero establece una relación entre la entidad divina y el alma: esta última recibe el influjo de Dios manifestado en forma luminosa y le devuelve a la misma divinidad su luminosidad, produciendo un cruce de iluminaciones y miradas que coincide con el funcionamiento físico del espejo y que da lugar a los efectos que se verán más abajo; el segundo, como se explicará, aplica en cambio las leyes de la refracción al tema de la memoria.

Uno de los poemas de Francisco de Aldana donde en la imagen del espejo mejor se condensa su elaboración filosófica y literaria es quizás el soneto LXIII, según la ordenación propuesta por Lara Garrido:

Seńor, que allá de la estrellada cumbre

todo lo ves en un presente eterno,

mira tu hechura en mí, que al ciego infierno

la lleva su terrena pesadumbre.

Eterno Sol, ya la encendida lumbre

do esté mi alegre abril florido y tierno

muere, y ver pienso al más nevado invierno

más verde la raíz de su costumbre.

En mí tu imagen mira, joh Rey Divino!, con ojos de piedad, que al dulce encuentro de tal rayo celestial verás volvella,

que a verse como en vidrio cristalino

9. Chastel (1982: 318). La presencia de los espejos en las tradiciones filosóficas hasta el Renacimiento está perfilada en Cancelliere (1989). Interesantes son también las reflexiones de Juan Carlos Rodríguez (2001) acerca del espejo como instrumento burgués, que sin embargo van más allá del asunto que nos ocupa: retomando los estudios de Vincent (2001), el cada vez más frecuente utilizo del espejo en el ámbito doméstico implica un cambio profundo en la mirada del sujeto, que ya no vincula su identidad a la mirada del otro, sino que empieza a definirse a sí mismo según su propia mirada y mirándose además en su completa desnudez.

10. Cerrón Puga (1984: 183-184).

11. García (2010: 68). 
la imagen mira el que se espeja dentro, y está en su vista dél su mirar della. ${ }^{12}$

En la nota que acompaña el texto, explica Lara que «el entrecruzamiento de imagen y luz [...] culmina en la unión mística; [...] la unión por amor [está] representada en el símil especular, por el que el lumen gloriae se equipara a dos espejos 'uno frente al otro; el uno recibe plenamente la imagen del otro, con la propia impresa ya en el otro'(Herp 1974: 357)». ${ }^{13} \mathrm{El}$ «rayo celestial» y la superficie de "vidrio cristalino" muestran en el soneto la lógica renacentista y neoplatónica del espejo, que en este caso refleja la mirada misma. ${ }^{14}$ Rivers explica que el soneto encierra en sí «la doctrina de la gracia prevenente, parte integral de la filosofía neoplatónica» ${ }^{15}$ y como se puede imaginar se trata de una reelaboración poética de la imagen del rayo de luz que proviene de la divinidad y que Ficino expone de la siguiente manera:

Dios, sin duda, como muestra la inteligencia que es su rayo, es luz invisible, infinita verdad, causa de cualquier verdad y de todas las cosas, cuyo esplendor, por mejor decir, cuya sombra, es esa luz visible y finita, causa de lo visible. [...] A partir de ahí la misma luz infusa en la mente angélica se resuelve en la inteligencia, pero por encima de los términos de la razón. Esta luz divina y angélica llega a las inteligencias de los hombres de acuerdo con la razón, pero supera a la fantasía. ${ }^{16}$

El rayo de luz no se propone solo como emanación de la divinidad con un poder vivificador, sino que se afirma también como instrumento con el que el hombre puede llegar a conocer a la divinidad misma. Impactando sobre la superficie del espejo, el rayo de luz permite entender cuál es la lógica luminosa (y la ley de la física) con la que se justifica la imagen del espejo como instrumento de conocimiento; al romper la linealidad del rayo de luz y al generar así refracción, el espejo genera también una iluminación interior:

entonces se produce el efecto del espejo, el desdoblamiento. De la parte de allá del espejo está la belleza iluminada por Dios en sus diferentes formas y matices, pero también de la parte de acá la fecundidad del alma reproduce un microcosmos resplante-

12. Francisco de Aldana (1985: 433-434). Todas las citas de los poemas de Aldana proceden de esta edición.

13. Lara Garrido (1985: 434).

14. «El sol que vemos, sombra de la luz invisible, vivifica los cuerpos al verlos (es decir al iluminarlos: la vista es emisión de rayos, no se olvide), muestra la consistencia del universo (es, pues, una luz inteligible) y al iluminar las cosas establece su verdad (es luz, por tanto, inteligente). Los mismos atributos convienen al alma, si imaginamos la luz concentrada en un sólo punto, la mens, como si fuera el foco de un espejo cóncavo: desde ese punto inmaterial se difunde la vida y se hace inteligible» (Bosco y Jiménez 2004: 194).

15. Rivers (1955: 163).

16. Ficino (2004: 339; 345). 
ciente [...]. El espejo es la imaginación. El espejo nunca refleja lo que representa. Símbolo de lo escindido, de hecho rompe la linealidad del rayo de luz, produciéndose la refracción. Los ojos que miran el espejo, buscando la identidad, jamás creerán en la fidelidad total del aspecto fantástico e ilusorio de las imágenes que aparecen en la superficie fronteriza. En este espejo, la iluminación más fuerte es la interior, no la que viene del lado del espejo, sino la que procede de los ojos interiores que miran la imagen fantasmagórica que hay en el espejo. Los ojos que miran de la parte de acá, los ojos interiores, saben de una realidad más sentida, más vivida. [...] Así, los ojos del cuerpo y el spiritus necesitan de la presencia ante el espejo, la imaginación. Pero no así el alma, que por medio de la memoria va coleccionando las imágenes del espejo. ${ }^{17}$

El círculo de la luz emanada por la verdad divina se convierte en espiral: la luz divina que armoniza el universo ahora cuenta con un reflejo —el alma humana - que recoge la forma del mundo y la armoniza, estableciendo por consiguiente el sentido del cosmos.

El espejo concretiza la reciprocidad que existe entre la divinidad y el alma, entidades separadas que sin embargo se ponen en relación precisamente a través de la refracción de la luz. Esta isocronía de efecto repetitivo y visión es subrayada también por Lara Garrido, ${ }^{18}$ quien evidencia que el símil de los dos espejos opuestos que intercambian sus imágenes establece en Aldana un nuevo modelo analógico para la contemplación: "La visión divina desde un 'presente eterno' deviene, en los intercambios oculares de su imago animista, espejo insondable que refracta sin término la alteridad gemela, la transmisión del deseo con la mirada en que su 'luz vital' concede a los ojos 'virtud visiva'» (96). Es lo que ocurre en el soneto propuesto arriba, pero también en la Carta para Arias Montano, donde la refracción del rayo de luz produce nuevos rayos, emanados por «el cristalino humor que está en los ojos / espejos de natura propiamente»: ${ }^{19}$

en quien hiriendo el sol con luz serena,

echan como de sí nuevos resoles

do el rayo visüal su curso enfrena. ${ }^{20}$

Volviendo por un momento al soneto LXIII, también Alexander Parker otorga a la contemplación especular cierto recorrido circular: «Dios mira al hombre como quien se contempla en un espejo, y ve en él su propia semejanza». ${ }^{21}$ Las leyes de la física contribuyen a la solidez de la metáfora del espejo, a través de la cual se entiende cómo en la superficie especular del alma se refleja la imagen de la divinidad,

17. Villa Ardura (2001: XL).

18. Lara Garrido (1985: 95).

19. Francisco de Aldana (1985: 363 , vv. 117-118).

20. Francisco de Aldana (1985: 456, vv. 379-381).

21. Parker (1986: 86). 
que sin embargo, precisamente como el rayo de sol que rebota en un espejo, regresa hacia la divinidad misma recuperando el sentido de la recíproca iluminación platónica y afirmando de manera definitiva la centralidad ${ }^{22}$ del alma humana en la doctrina neoplatónica, ya que dentro de la escala de los seres el alma es la única cuyo privilegio es el de convertirse en espejo para el rayo divino: «de acuerdo con el neoplatonismo de la luz y de la vista, la 'imagen' de Dios que está en el hombre se vuelve desde él hacia el sol eterno, para encontrarse con el rayo celestial o divino", estableciendo por lo tanto una "comunión ocular». ${ }^{23}$

El juego de luces reflejadas y del doble espejo que conecta el alma con la divinidad vuelve a aparecer en los tercetos del soneto XXX:

[...]

Tal tú, mi nuevo Apolo, el ser perfeto cobrando yo a tu luz, que así a menudo de mi vivir la estambre va tejiendo;

el rayo reverbera en mí, sujeto

de tu alabanza, y quedo ciego y mudo, por bien celeste un dulce mal sufriendo. ${ }^{24}$

Como señala García, se trata de un Aldana «animista religioso» que de nuevo acude al neoplatonismo en su relación entre vista y luz y que condensa en estos endecasílabos el recorrido lumínico de la imagen divina hacia y desde el alma humana:

El planteamiento es sutilísimo. Rivers (1955: 163) acude al Hebreo para el que, si nuestros ojos no fueran alumbrados por la luz del sol, nunca lo veríamos, porque sólo con el sol se ve el sol. [...] Siguiendo a Rivers, Ruiz Silva (1981: 131), para quien el 'sentido del anhelo místico' está muy presente en el poema, escribe lo siguiente: 'En los tercetos el poeta pide a Dios que le mire y así poder él mirarlo, pues la luz de Dios es la única que puede hacerle ver a Dios. La fusión de las miradas, en el último terceto, responde a la tradición neoplatónica que encontramos en los Diálogos de amor de León Hebreo y en el Cántico espiritual de San Juan de la Cruz. [...] Tras remitir a Rivers y a la doctrina de la 'gracia preveniente' de la filosofía platónica que éste ilustra con Hebreo, Lara Garrido (1985: 433) indica cómo Aldana recurre al 'tipo paulino' según el cual el hombre está resplandeciendo con su imagen en la imagen divina, por lo que — parafraseando a Eckhart — la unidad del hombre y de Dios debe concebirse de acuerdo con la semejanza de la imagen, dado que el hombre se parece a Dios con respecto a la imagen..$^{25}$

22. Según Ficino, la divinidad «se refleja en tres espejos diferentes colocados en orden, en el ángel, en el alma y en el cuerpo del mundo» (Parker 1986: 95).

23. García (2010: 661-662).

24. Francisco de Aldana (1985: 235).

25. García (2010: 661). 
Subrayando la unión mística del alma con la divinidad a través del símil especular, sugiere Lara Garrido ${ }^{26}$ que este soneto puede relacionarse con El parto de la Virgen (poema XLIII), entre otros poemas en los que se desarrolla el mismo principio místico de refracción divina:
[...]
La Causa universal, sola y primera, de cuanto vive, entiende, es, crece y siente, su luz que él en sí mismo reverbera mira, y la lumbre de ambos procediente; mírase el centro que es su propia esfera, Dios único, infalible y trascendiente, mírase no de nuevo, mas de modo que estando todo en él se mira en todo. ${ }^{27}$

«En la bifocalidad de los espejos paralelos cualquier mirada lumínica se ensimisma», ${ }^{28}$ afirma Lara en relación a los intercambios oculares y especulares que favorecen la unión mística; sin embargo, hay algunos versos de Aldana en los que la luz adquiere propiedades más concretas y establece conexiones no solo con la divinidad sino también con la memoria y con cierto grado de tensión deseante, enlace que por consiguiente nos llevará a la reelaboración lumínica y especular que Luis Cernuda opera a partir de la lectura de Aldana.

A través de las palabras de Villa Ardura, ya antes se ha recordado cómo el alma, a través de la memoria, colecciona imágenes del espejo. ${ }^{29}$ Dicha extensión de la 'reflexión' especular al tema del recuerdo puede empezar a notarse en versos de Aldana como los siguientes, procedentes del poema L, Carta a un amigo, al cual le llama Galanio...:

[...]

a la imaginación solté la rienda

y comenzaron dentro, al claro rayo

del Sol del alma, que alumbrando estaba

como a inferiores cielos sus potencias,

infinidad de imagines sensibles

a rebullir con hervorosa priesa

[...]

tal fue la muchedumbre abundosísima

de la movilidad de mis especies

espiritualizadas [...]

que el rayo despertó, mental y puro,

26. Lara Garrido (1985: 434).

27. Francisco de Aldana (1985: 328, vv. 756-760).

28. Lara Garrido (1985: 96); cf. además Nievas (2016).

29. Villa Ardura (2001: XL). 
el cual no estando al órgano ligado

de facultad corpórea, reverbera

sobre sí misma y siente sus noticias. ${ }^{30}$

Más allá de la renovación del modelo renacentista de la epístola horaciana, gracias al «motivo de la identificación con el receptor, asumido como amicitia que completa el alma y la vida", ${ }^{31}$ lo que aquí interesa es la memoria despertada por el rayo: «Entonces la memoria, tesorera / de aquella y de esta inmaterial riqueza, / [...] / como tocada fue, como la hiere / relámpago de luz tan repentino». ${ }^{32} \mathrm{Sin}$ olvidar el corte animista de los versos, por la referencia al «Sol del alma», entre otras cosas, ${ }^{33}$ se recuperan aquí conceptos aristotélicos relacionados precisamente con el tema del recuerdo, como explica Lara Garrido recogiendo una cita de Francisco de Herrera: «La memoria 'como piensa Aristóteles es imaginación de aquellas cosas que había hallado el sentido, como simulacro de aquéllas de quien nació la imaginación'». ${ }^{34}$ En los versos propuestos, el rayo de luz no provoca juegos de refracciones, sin embargo, de la misma manera, desata "propiedades lumínicas del entendimiento» 35 que estimulan las propiedades imaginativas del alma y que se multiplican en muchos «luminosos rayos» (v. 53), rayos que — ahora sí- rebotan sobre otras imágenes mentales a manera de espejo; volviendo a conferir al entendimiento propiedades lumínicas recordando al Herrera de las Anotaciones, Lara Garrido explica el concepto de fantasía en Aldana, en estrecha relación con el concepto de luz que permite representar «de tal suerte en el ánimo las imágenes de las cosas ausentes que nos parece que las vemos con los ojos y las tenemos presentes»: ${ }^{36}$

[...]

de mi Galanio la lucida imagen

[...]

Luego la luz del que preside dentro, mirando la querida semejanza

llovió sobre ella luminosos rayos de nunca vistos tales resplandores, cuyo mental vigor saca y destila de la sensible especie otra que viene inteligible a ser de su manera. ${ }^{37}$

30. Francisco de Aldana (1985: 359-360, vv. 11-16, 26-28, 31-34).

31. Lara Garrido (1985: 35).

32. Francisco de Aldana (1985: 361, vv. 62-63, 67-68).

33. Cf. García 2010: 484.

34. Lara Garrido (1985: 361).

35. García (2010: 486).

36. Lara Garrido (1985: 359).

37. Francisco de Aldana (1985: 360-361, vv. 43, 51-57). 
No se desata aquí un juego de recíproca iluminación platónica, como ocurre en el soneto LXIII, sino que ahora el rayo de luz produce un tipo diferente de refracción luminosa, que pone en marcha otra propiedad del alma conectada con la memoria y que le permite a la mens multiplicar imágenes a partir de un recuerdo, como se va a explicar a continuación. El rayo de luz vuelve a aparecer con esta misma propiedad en el poema XXXV, Respuesta a Cosme de Aldana, su hermano, desde Flandes:

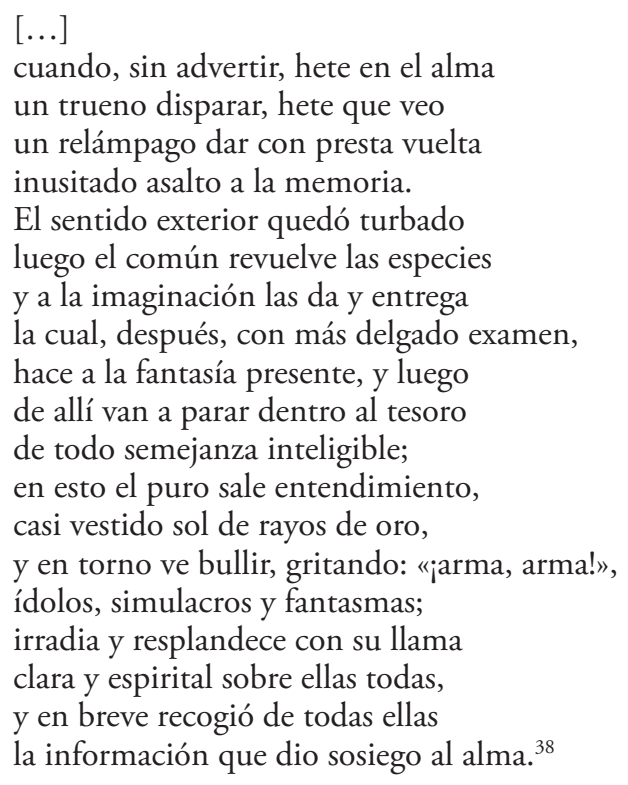

Como se puede entender fácilmente, también en este poema la iluminación repentina del relámpago desata una serie de imágenes que surgen precisamente a partir del asalto luminoso a la memoria; de ahí vuelve a producirse una nueva refracción que «irradia y resplandece con su llama» sobre todas las imágenes que se han producido en la mente del poeta y que van a confluir en la imagen final de su hermano, Cosme, que se queda por encima de todas las demás. El procedimiento es el mismo que se había producido en la Carta a Galanio, pero mientras allí la imagen de Galanio había emanado rayos que habían iluminado otros recuerdos, aquí los diferentes rayos surgidos del relámpago que rebota en la memoria convergen, a manera de espejo, en la imagen única de Cosme, volviendo a confirmar las propiedades físicas y convergentes del rayo.

Si en el poema LXIII la luz divina se reflejaba en el alma, produciendo un rayo que volvía hacia la divinidad misma según las leyes físicas de refracción especular, ahora el alma funciona como espejo también entre la luz metafórica,

38. Francisco de Aldana (1985: 276-277, vv. 5-23). 
catalizadora del recuerdo, y la memoria, cuyas imágenes resplandecen gracias a los rayos reflejados. La figura y el valor de la luz que rebota en un espejo cobra aquí un segundo valor: se ha visto como sintonía entre el orden del mundo y la mirada y ahora aparece como signo de la inteligencia creadora que facilita un estado de quietud, de armonía («la información que dio sosiego al alma», poema XXXV, v. 23).

\section{Aldana metafísico: la lectura de Luis Cernuda}

La poesía contemplativa de Aldana se convierte en modelo, junto a la de otros cuantos poetas, para un «clásico contemporáneo como Luis Cernuda, [quien] lo actualizó, lo trajo a su presente». ${ }^{39} \mathrm{~A}$ raíz de su exilio, al entrar en contacto con la tradición metafísica anglosajona, Cernuda ve reflejarse la propia dualidad entre realidad y deseo en la "polarización" que reconoce en el Aldana 'metafísico' entre realidad visible e invisible: ${ }^{40}$

respecto de Aldana las formas visibles no tienen ya realidad sino al desdoblarse en imagen interior. [...] Hay en la posición mística de Aldana un elemento pasivo mayor que en San Juan, aunque también haya un elemento activo, que es el amor. Con su intervención éste mitiga la tendencia quietista que tan evidente parece, pues el alma va a anegarse en Dios como los ojos van «sabrosamente al sueño ciego». La inmortalidad a que aspira no es la exaltación personal del ser terreno, tal en Manrique, sino el enajenamiento del mismo en su Hacedor, sin conservar de sí otro atributo que el impulso amoroso individual, el cual es, respecto de Dios, como el aire respecto de la luz por él extendida. ${ }^{41}$

El elemento activo y amoroso que Cernuda identifica en la poesía de Aldana podría volver a explicarse a través de las bases lumínicas ficinianas y de los principios especulares que vinculan la unidad del cosmos con las propiedades del alma: la imagen del espejo cóncavo elaborada por Ficino, ${ }^{42}$ una imagen-talismán en opinión de Bosco y Jiménez, "hace efectivo el paralelo entre alma y universo y lo prolonga explícitamente hasta niveles afectivos, porque en ámbos espejos cóncavos la luz concentrada se conviere en calor». ${ }^{43}$ La valorización del retorno de la forma sensible a la Idea, a través del desdoblamiento subrayado por Cernuda en la poética de Aldana, supone la cima de lo que se ha venido diciendo hasta aquí acerca de la imagen interior o imagen humana del mundo. La imagen interior es sobre todo conformadora de un nuevo tipo de lo humano y en ella se puede advertir una dimensión simbólica metafísica por la que el sentido que el

39. García (2010: 19).

40. Cf. Lara Garrido (1985: 14) y Cernuda (1994: 508).

41. Cernuda (1994: 510-511).

42. Véase supra, nota 22.

43. Bosco y Jiménez (2004: 194-195). 
arte poética establece en el mundo se presenta como instrumento para intentar alcanzar la verdad de las cosas. El amor de Aldana al que hace referencia Cernuda es un amor de derivación totalmente platónica, es la substantivización de la tensión simbólica y deseante retomada directamente del Banquete de Platón: «la razón de esto es que nuestra antigua naturaleza era como se ha descrito y nosotros estábamos íntegros. Amor es, en consecuencia, el nombre para el deseo y persecución de esta integridad». ${ }^{44}$

El Deseo, por lo tanto, en principio empezaría a vislumbrarse en Cernuda también como deseo de reunificación con una verdad superior de la que el alma tiene conciencia al haber sido separada de ella, un deseo de «anegarse», retomando las palabras de Cernuda a propósito de Aldana y que el sevillano aplica también a su misma poética, pero con matices de inmanencia que se van a explicar a continuación:

El instinto poético se despertó en mí gracias a la percepción más aguda de la realidad, experimentando, con un eco más hondo, la hermosura y la atracción del mundo circundante. Su efecto era, como en cierto modo ocurre con el deseo que provoca el amor, la exigencia dolorosa a fuerza de intensidad, de salir de mí mismo, anegándome en aquel vasto cuerpo de la creación. Y lo que hacía aún más agónico aquel deseo era el reconocimiento tácito de su imposible satisfacción. ${ }^{45}$

Ya en 1962, el célebre artículo de José Ángel Valente en el número de $L a$ caña gris de homenaje a Luis Cernuda resultó muy sugerente para futuros trabajos sobre los reflejos de los versos de Aldana en la obra del poeta sevillano; en este sentido, una propuesta ha sido perfilada por ejemplo por Martínez Abascal, entre otros, y en su trabajo también se hace una distinción muy precisa entre la vertiente religiosa de Aldana y la postura cernudiana: «si en Aldana ese mundo de belleza y concordia se alía a la imagen de Dios, en Cernuda asistimos a un doble conflicto, puesto que a un mundo devorado por la guerra y la crisis se suma la pérdida de la fe religiosa». ${ }^{46}$

El acercamiento de Cernuda a la poesía inglesa le aporta elementos estéticos que pudo rastrear en la tradición española no contemporánea a él ${ }^{47}$ y en la que se producía la misma tensión deseante que siente adecuada para expresar la acepción filosófica de su deseo, «la fuente del sentido en la inmanencia». ${ }^{48}$ Como

44. Platón (1998: 228).

45. Cernuda (1971: 151).

46. Martínez Abascal (2005: 408).

47. «El encuentro de Cernuda con la tradición poética inglesa es a la vez un encuentro con los elementos de la tradición propia gracias a los cuales dicha experiencia iba a resultar posible y fecunda. De ahí que desde su madurez de escritor llegue Cernuda a una intensa valoración de toda una zona de nuestra lírica en la que figuran Jorge Manrique, Aldana, la Epístola moral a Fabio o San Juan de la Cruz» (Valente 1962: 32).

48. Zubiaur (2002: 49). 
se ha visto antes, se trata de un deseo que surge de la conciencia de un dualismo casi platónico, pero, por mucha importancia que tenga, la centralidad del Deseo en la obra de Cernuda no puede reducirse a una reelaboración neoplatónica, sino que hay que tener en cuenta la familiaridad del sevillano con el pensamiento de Hölderlin, Schopenhauer y Nietzsche, por ejemplo. Sin embargo, su acercamiento a los metafísicos del siglo XVII y a la filosofía neoplatónica permite vislumbrar en algunos de sus poemas esa misma correlación entre la realidad visible y la invisible por medio de un símbolo, el del espejo, que podría haber recuperado de los versos de Aldana.

Limitándose al ámbito del neoplatonismo, en la poesía de Cernuda el deseo sirve de impulso para una progresión, que sin embargo consiste más en la persecución de un objeto que se aleja infinitamente y que, por consiguiente, implica un movimiento igualmente sin fin. Se trataría de un deseo eternamente en movimiento, pero antes habría que aclarar la dinámica circular de dicho deseo, donde la circularidad ya no se produce a manera de espiral entre la divinidad y el alma como ocurre en los versos de Aldana, sino que se afirma casi como una condena, un círculo sin fin de la inmanencia humana:

El neoplatonismo, basándose en Plotino más aún que en Platón, había consagrado la metáfora de la escalera: para salvar una distancia vertical que es gradual, el amor aporta la fuerza ascensional; pero al final hay una meta (donde cesa el deseo). Al mermar las diferencias entre los grados $y$, sobre todo, al difuminarse la cumbre, la escalera se tambalea: ya no hay altura sólida que la sostenga. Pero por mucho que caiga, que se horizontalice, el Deseo seguirá impulsando. Su movimiento no podrá ya ser una ascensión: a lo sumo un avance, un recorrido. Cuando sucumba la trascendencia como lugar de privilegio metafísico, el empuje del Deseo no operará una elevación metafísica, sino una expansión ontológica. ${ }^{49}$

Debido a su inmanentismo trágico, no pueden buscarse en Cernuda huellas de una metafísica religiosa propiamente dicha (si no es por negación), sino que hay que entender su Deseo precisamente como tensión, como aspiración a una redención estética de la existencia a pesar de la Realidad, que al Deseo se opone constantemente..$^{50} \mathrm{Si}$ el alma de Aldana poeta, en palabras de Cernuda, se anega en Dios es porque en ella sigue vivo el recuerdo de un estado divino anterior; Cernuda, en cambio, se anega «en el vasto cuerpo de la creación» porque en su

49. Zubiaur (2002: 58).

50. «Comencé a distinguir una corriente simultánea y opuesta dentro de mí: hacia la realidad y contra la realidad, de atracción y de hostilidad hacia lo real. El deseo me llevaba hacia la realidad que se ofrecía ante mis ojos como si sólo con su posesión pudiera alcanzar certeza de mi propia vida. Mas como esa posesión jamás la he alcanzado sino de modo precario, de ahí la corriente contraria, de hostilidad ante el irónico atractivo de la realidad. Puesto que, según parece, ésa o parecida ha sido la experiencia de algunos filósofos y poetas que admiro, con ellos concluyo que la realidad exterior es un espejismo y lo único cierto es mi propio deseo de poseerla» (Cernuda 1971: 155). 
interior no reverbera la memoria de sustancia eterna alguna, sino que el Deseo se queda horizontal, a nivel de la tierra (en el poema "Los fantasmas del deseo», por ejemplo ${ }^{51}$ y además, ya a partir de Primeras poesías, el mismo sujeto poético se afirma como el producto de su cuerpo deseante, como «memoria de hombre»:

[...]

Vivo un solo deseo,

Un afán claro, unánime;

Afán de amor y olvido.

Yo no sé si alguien cae.

Soy memoria de hombre;

Luego, nada. Divinas

La sombra y la luz siguen

Con la tierra que gira. ${ }^{52}$

A partir de este núcleo de tensión deseante compartida entre Cernuda y la vertiente metafísica de la poesía de Aldana, puede empezar a vislumbrarse la reelaboración que el sevillano hace de las imágenes lumínicas y especulares. Se trata, como se verá, de una operación que empieza a partir de los mismos conceptos neoplatónicos de refracción y que, sin embargo, se afirman por negación dejando al deseo como único motor de progresión (aunque circular y horizontal). Es lo que ocurre, por ejemplo, en el famoso poema "Apologia pro vita sua», de Como quien espera el alba, «Donde nada interrumpe el gobernar oscuro / [...] / Sino el rayo de sol, cuando penetra / Furtivo en el desván por un postigo hendido / Para agitar los sueños del polvo en formas grises» (vv. 7-11). Es este uno de los libros en que más presente está la correlación entre el mundo visible el invisible (Lucifora 2011-2012) y en que también se percibe la fuerza de la influencia bíblica, puesto que, como el mismo

51. «Tú sola quedas con el deseo, / Con este deseo que aparenta ser mío y ni siquiera es mío, / Sino el deseo de todos, / Malvados, inocentes, / Enamorados o canallas. // Tierra, tierra y deseo. / Una forma perdida» (Cernuda 1994: 109).

52. Cernuda (1991: 20). No hay que olvidar, sin embargo, que la tradición humanista y petrarquesca hace de la contraposición entre luz y tinieblas una de las más sólidas metáforas topológicas para aludir al olvido en la ausencia. En este sentido también algunas imágenes de Aldana se construyen a través de la dialéctica entre luz y oscuridad, pero no llegan a significados propiamente metafísicos, sino que de momento aluden a una dialéctica presencia/ausencia amorosa (poema L, vv. 374-376, por ejemplo) o de amistad (poema XIV). En el recorrido de ascensión neoplatónica nos encontramos todavía en un primer nivel sensitivo y hedonista: «la primera referencia al ejercicio de la amistad tiene lugar en el ámbito sensual de la práctica hedonista, donde la presencia física es necesaria, así como la luz que ella misma representa. [...] Los elementos que se concentran en torno al núcleo de la luz aún están lejos de funcionar como imágenes de la virtus o la caritas, pues se realizan bajo la dinámica del eros pandemos. Nos encontramos al comienzo de un puente que va del amor sensitivo al amor intelectual. Diferentes estadios conforman el camino, pero ninguno más sensitivo, más concupiscente que este primer estadio que en Aldana se alinea con los tratados que defienden, desde la esperienza, la voluptas como finalidad última del amor» (Nievas Rojas 2016: 414). 
Cernuda explica en Historial de un libro, la Biblia es una de las lecturas que acompañan sus años en Cambridge, donde en 1944 termina el poemario en cuestión. ${ }^{53}$

Es relevante que en "Apologia pro vita sua" se establezca una relación entre la presencia divina y la imagen del espejo; sin embargo, el significado aquí se subvierte con respecto a la luminosidad de los versos de Aldana y la subversión se hace más evidente aún debido al contraste entre luz y «el gobernar oscuro» que recorre el poema entero:

$[\ldots]$

Dejadles que se acerquen a mi cama

Y alumbren sus semblantes, como estrellas

Suspensas en la noche sobre el agua oscura

(vv. 16-18)

$[\ldots]$

De todos esos años ya pasados,

Llevándose mi vida, sólo quedan,

Como cirio que arde en cueva oscura

Y mueve sombras vagas sobre el muro,

Recuerdos destinados a morir de mi olvido.

(vv. 63-67)

[...]

Cuán hermosa la luz parece ahora

Temblando en halo azul tras de las ramas

Pardas de invierno donde brilla el hielo.

La renuncia a la luz más que la muerte es dura.

(vv. 87-90)

Aunque sean evidentes las referencias platónicas y neoplatónicas - hasta en el símbolo de la cueva - y pueda establecerse un vínculo con las imágenes de Aldana lumínicas y de amistad o de amor, ${ }^{54}$ la luz cernudiana en este poema parece siempre muy débil en su contraste con la oscuridad. También el léxico escogido por Cernuda («imagen», "alma») remite inevitablemente a esquemas neoplatónicos, pero en la última estrofa sobre todo resulta contundente la imposibilidad de refracción divina (que ya se ha anticipado en los «cristales ciegos» del v. 14); a través de la imagen de un espejo vacío, parece ponerse en duda la existencia de Dios, casi afirmando que se trata de una invención del hombre:

53. «Entre mis lecturas de esos años quisiera mencionar cómo, ya en Glasgow, había comenzado todas las noches a leer, por costumbre, una vez acostado, algunos versículos de la Biblia en traducción inglesa; de dicha lectura quizá debe quedar huella, entre otros versos míos, en algunos de los de Como quien espera el alba» (Cernuda (1958) 1991: 407).

54. Cf. Fosalba (1992) y Nievas Rojas (2016). 
Para morir el hombre de Dios no necesita,

Mas Dios para vivir necesita del hombre.

Cuando yo muera, ¿el polvo dirá sus alabanzas?

Quien su verdad declare, ¿̇erá el polvo?

Ida la imagen queda ciego el espejo.

(vv. 121-125)

Si Aldana prefiere el ejercicio de la soledad para alcanzar la plenitud (en la estela del viaje espiritual de derivación homérica o de la petrarquesca «De vita solitaria») y para estar "lejos del mal que el bien pueda estorbarte» (poema XXXI, Sobre el bien de la vida retirada, v. 303), aun ejerciendo la misma soledad, Cernuda casi prefiere enfrentarse a ese «mal» sumándole a la tradición heredada por Aldana la influencia del Romanticismo y la gran lección de Goethe ${ }^{55}$ con el Fausto. En «Noche del hombre y su demonio», también de Como quien espera el alba, la voz poética mantiene un monólogo dialogado con el demonio, un «demonio de andar por casa» como explica José María Vaz de Soto en su pormenorizado análisis del poema; ${ }^{56}$ se trata de un demonio que "es también Luis Cernuda en la figura de un Mefistófeles irónico, entre el ángel de la guarda y demonio de la compañía, y tan poco satánico que hacia el final del poema él mismo acaba poniendo en duda su naturaleza demoníaca». ${ }^{57}$ No se produce, como en los poemas de Aldana, un fenómeno propiamente dicho de refracción de rayos de luz, sin embargo sí están presentes en el largo poema de Cernuda las dos imágenes literarias de la luz y del espejo relacionadas con la presencia divina (o demoniaca). En la última estrofa, el demonio plantea definitivamente la posible ambivalencia y lo hace en el momento del alba, un momento liminal que se añade a la sensación (frustrada) de espera. Como se explicará a continuación, este concepto de espera junto a la iluminación, de clara derivación platónica, contribuye a la consolidación del sentido simbólico de esa tensión deseante compartida por los dos poetas. Además, dicho sentido simbólico, se enriquece gracias a una de las imágenes literarias que más significación tiene en la poética cernudiana, la ventana:

$[\ldots]$

D: Después de todo, ¿quién dice que no sea

Tu Dios, no tu demonio, el que te habla?

Amigo, ya no tienes sino es éste

Que te incita y te despierta, padeciendo contigo,

Mas mira cómo el alba a la ventana

55. La lectura del autor alemán también se remonta a los años de estancia en Cambridge (cf. Cernuda 1991: 407).

56. Vaz de Soto (2011: 82).

57. Vaz de Soto (2011: 76). 
Te convoca a vivir sin ganas otro día.

Pues el mundo no aprueba al desdichado,

Recuerda la sonrisa y, como aquel que aguarda,

Alzate y ve, aunque aquí nada esperes.

(1991: 233)

Como se sabe, la ventana es una de las imágenes más fecundas de Luis Cernuda ya a partir de Primeras poesias, donde «es la apertura en la pared de la casa, de la habitación — reflejo interior estático del sujeto-, por la que penetran las sensaciones inalcanzables del mundo, las múltiples posibilidades que siente estar perdiendo». ${ }^{58}$ Mucho se ha dicho de las ventanas cernudianas como objeto de separación sin apenas posibilidades de comunicación entre el interior y el exterior, ${ }^{59}$ pero más que en esta vertiente quiero centrarme tanto en las posibilidades de reflexión física de esta imagen, como en su propiedad de objeto liminar (y no de barrera insuperable). No se trata de un espejo en el que rebota la luz, pero de todas formas la ventana permite una iluminación del sujeto, que a su vez se refleja en el cristal casi renovando el mito de Narciso. Además, como explica Ibánez, en los años ingleses de composición de Vivir sin estar viviendo (cuyo primer poema es precisamente "La ventana»), la perspectiva ha cambiado mucho en Cernuda con respecto a Primeras poesias: «ahora el poeta ha vivido, y la mirada, el poema, reflexiona desde esa atalaya improvisada». ${ }^{60}$ Lo atestiguan versos como los siguientes: «Y al poder te somete de unos ojos / Donde amanece el alma / Allá en su fondo azul, tranquilo y frío, / Hacia la luz alzados, / Unida a ellos, y unido tú con ellos / Por vida y muerte quieres contemplarlos» («La ventana», vv. 35-40).

Esta aptitud contemplativa y de consiguiente iluminación que permite la ventana, no puede no traer a la memoria los versos finales de la Carta al señor don Bernardino de Mendoza de Aldana (poema XLVI), donde vuelven a aparecer las «ventanas de oriente» en las que se había reflejado "la florida y tierna Aurora» de su poema XXXIII:

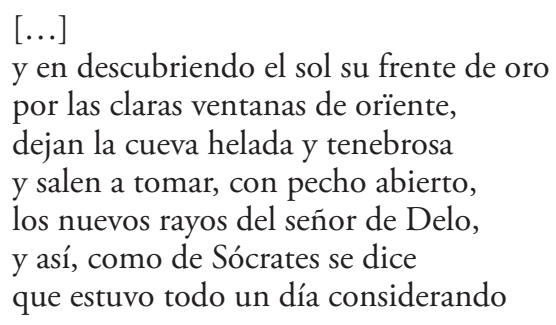

58. Ibáńez Avendaño (1994: 37).

59. Cf. Harris (1973) e Ibáńez Avendaño (1994).

60. Ibáñez Avendaño (1994: 40). 
la gran carrera del que alumbra al mundo, y que, sin pie mudar toda una noche, miran al matutino ojo del cielo, y a la pura en sí luz cómo en sí misma relampaguea con presurosa vuelta, no por parar allí, que no es objeto proprocionado al alma cuerpo alguno, mas por subir desde aquel Sol visible al invisible sol, autor del alma. ${ }^{61}$

Las referencias al alma en los versos de los dos poetas y su iluminación a través de una ventana (propiamente física en el caso de Cernuda y mucho más metafórica en el caso de Aldana) afirman definitivamente la propiedad simbólica de este objeto; es más, gracias a la penetración de la luz, a la consiguiente reflexión del sujeto sobre sí mismo y a la consiguiente iluminación de su alma con la que esta se reconoce parecida a algo trascendente, las ventanas podrían casi definirse no solo como símbolos sino como iconos, en la acepción etimológica del término: "del gr. eikôn, -ónos, 'imagen', deriv. de éoika 'me he asemejado'». ${ }^{62}$ Después de esta pequeña digresión acerca de las ventanas, volviendo a la «Noche del hombre y su demonio», en este poema se presenta al fin y al cabo la misma puesta en duda de la figura divina planteada en "Apologia pro vita sua»; ${ }^{63}$ lo que cambia es que ahora se ańade un desdoblamiento del poeta, que acaba reconociéndose a sí mismo en la figura del demonio/dios que refleja su imagen como en un espejo:

[...]

D: No sólo forja el hombre a imagen propia

Su Dios, aún más se le asemeja su demonio.

Acaso mi apariencia no concierte

Con mi poder latente: aprendo hipocresía,

Envejezco además, y ya desmaya el tiempo

61. Francisco de Aldana (1985: 351, vv. 139-151).

62. (Corominas 1987: 330). Se trata de una interpretación que empieza a partir de una postura puramente religiosa (de cristianismo ortodoxo) y que se aplica sobre todo al arte, pero también Florenskij (Las puertas reales, 1992) establece una comparación entre iconos y ventanas, definiendo estas últimas como figuración necesaria para "ver la divinidad» y para eliminar cualquier tipo de barrera entre las imágenes falaces de este mundo inmanente y la verdad. Es más: para explicar este concepto, el filósofo ruso se remite directamente a Plotino y a su teoría sobre el símbolo y la belleza de los cuerpos que permite ascender a la belleza única y universal. Gracias a estas teorías plotinianas, que ven en la belleza de los cuerpos el primer nivel de un recorrido ascensional, también se podría explicar el hedonismo que comparten las poéticas de Aldana y de Cernuda.

63. Sigue Vaz de Soto: «Ya en su segundo parlamento, D (inicial que obviamente puede serlo tanto de Demonio como de Dios), volviendo del revés la conocida frase bíblica acerca de la creación del hombre a imagen y semejanza de Dios, nos dice que es el hombre el que crea a imagen suya a Dios y, todavía más a imagen suya, a su demonio» (2011: 76). 
El huracán sulfúreo de las alas

En el cuerpo del ángel que fui un día.

En mí tienes espejo.

(1991: 231, vv. 17-24)

El reflejo y el reconocimiento en el demonio/divinidad permite otra profundización de carácter etimológico: es cierto que Cernuda elige el término 'demonio', que en sí encierra un rasgo de divinidad, ${ }^{64}$ pero también hay que considerar la existencia del término 'diablo' y centrarse sobre todo en su origen griego: «med. S. X. Tom. del latín tardío diabŏlus, y éste del gr. diábolos íd., propte. 'el que desune o calumnia' (deriv. de diabállō 'yo separo, siembro discordia, calumnio' de bállo 'yo arrojo'” (Corominas 1987: 212). Se trata de la misma diferencia entre 'demonio' y 'diablo' que plantea Jesús Aguirre en su prólogo a la edición española del Fausto de Goethe, ${ }^{65}$ pero lo que más interesa auquí es que, gracias a su reflejo y al reconocimiento de su doble, Cernuda está afirmando también la conciencia tanto de una fractura interior, como de una fractura de derivación platónica entre el hombre y una verdad superior, una separación (diabállōo). Por supuesto, esta fractura puede seguir profundizándose también a través de una lectura romántica, siguiendo la pista de la relación que se construye entre el neoplatonismo de Aldana y la metafísica anglosajona (y alemana) de la que ya se ha hablado arriba y que no es sino una extensión de la conciencia de la edad de la luz que se vive en el Renacimiento.

La conciencia de un estado de separación platoniano (diabállō) y el consiguiente deseo de reunificación están presentes también en Ficino:

Aquel que en el tiempo presente se consagra con amor todo entero a Dios, finalmente se reencontrará con él. Porque retornará a la idea por la que fue formado. Allí, si le faltase algo, será reformado, y estará unido a su idea eternamente. Pues un hombre verdadero y la idea del hombre es una misma cosa. Pero cualquiera de nosotros que está separado de Dios en la tierra no es un hombre, verdadero, porque está separado de su idea, y de su forma. El amor divino y la piedad nos conducirán a ella, pues como estamos aquí divididos y mutilados, unidos a nuestra idea al amar, llegaremos a ser hombres completos. ${ }^{66}$

De cierta manera, ya se ha explicado cómo podría realizarse la acción de reunificación y sería a través de esa tensión deseante que en Aldana tiene un recorrido ascensional y que en Cernuda se horizontaliza. De todas formas, esta tensión consiste en los dos casos en una actividad poética que se contrapone

64. «To. del lat. tardío daemonium íd., y éste del gr. daimônion 'genio, divinidad inferior', entre los cristianos 'demonio', diminutivo de dáimōn 'dios, divinidad'» (Corominas 1987: 204).

65. Aguirre (2011).

66. Ficino (1994: 185-186). 
al dia-bállō, confirmando su vertiente de creación en el sym-bállō, el símbolo poético. ${ }^{67}$

La creación poética vuelve finalmente a encontrar un asidero en la naturaleza especular en los versos de "El poeta» de Cernuda, donde de nuevo aparece un vocabulario neoplatoniano y donde casi parece oírse un eco de los versos de Aldana en su invocación a Apolo "que conforme al deseo vuele mi pluma, / pues conforme al deseo vuela el sujeto»: ${ }^{68}$

$[\ldots]$

Con reverencia y con amor así aprendiste,

Aunque en torno los hombres no curen de la imagen

Misteriosa y divina de las cosas,

De él, a mirar quieto, como

Espejo, sin el cual la creación sería

Ciega, hasta hallar su mirada en el poeta.

$[\ldots]$

Para el poeta hallarla es lo bastante,

E inútil el renombre u olvido de su obra,

Cuando en ella un momento se unifican,

Tal uno son amante, amor y amado,

Los tres complementarios luego y antes dispersos.

El deseo, la rosa y la mirada

(vv. 19-24, 37-42).

Se confirman, por lo tanto, los rasgos neoplatónicos de unión entre la poética de Francisco de Aldana y la de Luis Cernuda, unión que encuentra un asidero ulterior en la conexión que el sevillano reconoce entre la poesía y la experiencia mística: «la experiencia poética no es sólo más o menos simple, como ocurre en la mayoría de los poetas, sino que en ella en ocasiones la experiencia humana se desdobla, gracias a la proyección mística que conlleva, revistiéndose de un sentido hermético y mágico». ${ }^{69} \mathrm{~A}$ través de una contemplación previa, de una progresiva iluminación del mundo terrenal (deslumbrante en el caso de Aldana y mucho más tamizada en los versos de Cernuda) o, dicho de otra forma, por medio de una mirada neoplatónica que despierta la mirada interior, los dos poetas expresan su afán de reunificación, de superación de los límites de la Realidad bajo el impulso del Deseo.

67. «Símbolo, lat. symbŏlum. Tom. del gr. symbolon íd., deriv. de symbállō 'yo junto, hago coincidir' (y éste de bállō 'yo lanzo') (Corominas 1987: 536).

68. Francisco de Aldana (1985: 148, vv. 9-10).

69. Cernuda (1975: 1036) en Ali Abdel Azim (2017: 10). 


\section{Bibliografía}

Aguirre, Jesús, «Prólogo», en Johann Wolfgang Von Goethe, Fausto, Madrid, Austral, 2011.

Aldana, Francisco de, Poesías castellanas completas, ed. de José Lara Garrido, Madrid, Cátedra, 1985.

Ali Abdel Azim, Rasha, «Luis Cernuda: realidad, deseo y sanjuanismo», Dicenda. Cuadernos de filología hispánica, 35 (2017) 9-26.

Bosco Díaz-Urmeneta, Juan y Jiménez Manzorro, Pedro A., La tercera dimensión del espejo. Ensayo sobre la mirada renacentista, Sevilla, Publicaciones Universitarias, 2004.

Cancelliere, Enrica, «Celebración de la palabra en el poema de fray Luis», en Ciriaco Morón Arroyo y Manuel Revuelta Sañudo (eds.), Fray Luis de León. Aproximaciones a su vida y su obra, Santander, Sociedad Menéndez Pelayo, 1989, 169-201.

Cernuda, Luis, (1958), «Historial de un libro», en La Realidad y el Deseo (1924-1962). Seguido de "Historial de un libro», Madrid, Alianza, 1991.

—, (1964) «Tres poetas metafísicos», en Obra completa. Prosa I, ed. de Derek Harris y Luis Maristany, Madrid, Siruela, 1994.

—, «Palabras antes de una lectura», en Poesía y Literatura I, Barcelona, Seix Barral, 1971, 151-156.

—, Prosas completas, Barcelona, Seix Barral, 1975.

—, La Realidad y el Deseo (1924-1962). Seguido de "Historial de un libro», Madrid, Alianza, 1991.

Chastel, André, Arte y humanismo en Florencia en tiempos de Lorenzo el Magnifico, Madrid, Cátedra, 1982.

Corominas, Joan, Breve diccionario etimológico de la lengua castellana, Madrid, Gredos, 1987, 3a ed.

Ficino, Marsilio, De amore. Comentario a «El Banquete» de Platón, Madrid, Tecnos, 1994.

—, "Quid sit lumen», La tercera dimensión del espejo. Ensayo sobre la mirada renacentista, Juan Bosco Díaz-Urmeneta y Pedro A. Jiménez Manzorro, Sevilla, Publicaciones Universitarias, 2004, 335-350.

—, Métaphysique de la lumière (Opuscules, 1476-1492), ed. de Julie Reynaud y Sébastien Galland, Chambéry, L'act Mem, 2008.

Fosalba, Eugenia, «Francisco de Aldana, poeta de la presencia amorosa», Glosa, 3 (1992), 179-197.

García, Miguel Ángel, «Sin que la muerte al ojo estorbo sea». Nueva lectura crítica de Francisco de Aldana, Mérida, Editora Regional de Extremadura, 2010.

Harris, Derek, Luis Cernuda, a Study of the Poetry, Londres, Tamesis Books, 1973.

Herp, Enrique, Directorio de contemplativos, ed. de J. M. Kelly, Salamanca, Universidad Pontificia, 1974.

Ibáñez Avendaño, Begoña, El símbolo en "La Realidad y el Deseo» de Luis Cernuda. El aire, el agua, el muro y el acorde como génesis literaria, Kassel, Edition Reichenberger, 1994. 
KLeIN, Robert, La forma y lo inteligible. Escritos sobre el Renacimiento y el arte moderno, Madrid, Taurus, 1982.

Lara Garrido, José, «Introducción» a Francisco de Aldana, Poesías castellanas completas, ed. de José Lara Garrido, Madrid, Cátedra, 1985, 13-119.

Lucifora, María Clara, «El afán de ver. Pensamiento poético en 'Como quien espera el alba', de Luis Cernuda», Archivum, 61-62 (2011-2012), 273-304.

Martínez Abascal, Elena, "Correspondencias entre la obra de Francisco de Aldana y Luis Cernuda", Nostalgia de una patria imposible. Estudios sobre la obra de Luis Cernuda. Actas del Congreso "Luis Cernuda en su centenario" (León, 8, 9 y 10 de mayo de 2002), Madrid, Akal, 2005, 405-420.

Nievas Rojas, Adalid, «La amistad en la poesía de Francisco de Aldana», Studia Aurea, 10 (2016), 411-443. $<$ https://doi.org/10.5565/rev/studiaaurea.223>

Panowsky, Erwin, «El movimiento neoplatónico en Florencia y el norte de Italia», Estudios sobre iconología, Madrid, Alianza, 2008, 189-237.

PARKer, Alexander, La filosofía de amor en la literatura española (1480-1680), Madrid, Cátedra, 1986.

Platón, Diálogos III. Fedón, Banquete, Fedro, Madrid, Gredos, 1998.

Rabassini, Andrea, "Amicus lucis'. Considerazioni sul tema della luce in Marsilio Ficino", Marsilio Ficino. Fonti, testi, fortuna, Sebastiano Gentile y Stéphane Toussaunt (eds.), Roma, Edizioni di Storia e Letteratura, 2006, 255-294.

Rivers, Elias L., Francisco de Aldana. El divino capitán, Badajoz, Institución de Servicios Culturales de la Diputación Provincial, 1955.

Rodríguez, Juan Carlos, «La noche de Walpurgis: de Stoker a Borges», De qué hablamos cuando hablamos de literatura, Madrid, Debate, 2001, 377-411.

Ruiz Sisva, Carlos, Estudios sobre Francisco de Aldana, Universidad de Valladolid, 1981.

VAlente, José Ángel, «Luis Cernuda y la poesía de la meditación», La caña gris, 6-8 (1962), 29-38.

VAsolI, Cesare, «Su alcuni temi della 'filosofia della luce’ nel Rinascimento: Ficino ('De Sole' e 'De lumine') e Patrizi (libro primo della 'Panaugia'), Annali della Facoltà di Lettere e Filosofia dell'Università di Cagliari, 9, 47 (1988), 63-89.

VAZ DE Soto, José María, "Cernuda y su demonio», Boletín de la Real Academia Sevillana de Buenas Letras: Minervae Baeticae, 39 (2011), 74-84.

Villa Ardura, Rocío de la, «Introducción» a Marsilio Ficino, De amore. Comentario a "El Banquete» de Platón, Madrid, Tecnos, 2001, XI-XLIII.

Vincent, Gérard, «Il corpo e l'enigma sessuale», La vita privata. Il Novecento, Philippe Ariès y Georges Duby (eds.), Roma/Bari, Laterza, 2001, 151-154.

Zubiaur, Ibon, La construcción de la experiencia en la poesía de Luis Cernuda, Kassel, Edition Reichenberger, 2002. 